\title{
Erratum: The thermal impact of aquifer thermal energy storage (ATES) systems: a case study in The Netherlands, combining monitoring and modeling
}

\author{
Philip W. Visser • Henk Kooi • Pieter J. Stuyfzand
}

Erratum to: Hydrogeology Journal (2014)

DOI 10.1007/s10040-014-1224-z

There was a format conversion error during proof processing, and the first four equations were presented incorrectly in the published article. Under the heading 'Site models', equations 1, 2, 3 and 4 should read as:

$\rho_{\mathrm{a}} C_{\mathrm{a}}=\theta \rho_{\mathrm{w}} C_{\mathrm{w}}+(1-\theta) \rho_{\mathrm{s}} C_{\mathrm{s}}$

where $\rho$ is the density and $C$ the specific heat capacity of the aquifer (a), water (w) and solid matrix (s), and $\theta$ is the porosity.

$k=[\alpha \log w+\beta] 10^{0.00062 \rho \mathrm{d}}\left(\mathrm{W} \mathrm{m}^{-1} \mathrm{~K}^{-1}\right)$

$\alpha=(1.4241-0.00465 \times c) 10^{-1}$

$\beta=(0.4192-0.00313 \times c) 10^{-1}$

Also, under the heading 'Regional groundwater flow model' and subheading 'Calibration', the statistical parameters for the calibration include:

Residual mean: $-0.02 \mathrm{~m}$

Published online: 17 February 2015

(C) Springer-Verlag Berlin Heidelberg 2015

The online version of the original article can be found at http:// dx.doi.org/10.1007/s10040-014-1224-z.

P. W. Visser

Arcadis, PO Box 6737300 AR, Apeldoorn, the Netherlands

P. W. Visser $(\bullet) \cdot$ P. J. Stuyfzand

KWR Watercycle Research Institute, PO Box 10723430 BB,

Nieuwegein, the Netherlands

e-mail: philip.visser@arcadis.nl

Tel.: +31 (0)6 46647395

P. W. Visser · H. Kooi • P. J. Stuyfzand

Critical Zone Hydrology Group, Department of Earth Sciences,

VU University Amsterdam, De Boelelaan 1085, 1081 HV,

Amsterdam, the Netherlands 